\title{
THE APPLICATIONS OF SOME BASIC MATHEMATICAL INEQUALITIES ON THE CONVERGENCE OF THE PRIMITIVE EQUATIONS OF MOIST ATMOSPHERE
}

\section{Li Yuanfei* ${ }^{*}$ Xiao Shengzhong And Zeng Peng}

\begin{abstract}
In this paper, we show the applications of some basic mathematical inequalities in partial differential equations. By using the differential inequality technique, the convergence of the primitive equations of moist atmosphere is obtained
\end{abstract}

Mathematics subject classification (2010): 35K05, 35K20, 35K55.

Keywords and phrases: Sobolev inequalities, convergence, primitive equations.

\section{REFERENCES}

[1] L.E. PAYNE, Uniqueness criteria for steady state Navier-Stokes equations, Simpos. Internaz. Appl. Anal. Fis. Math., Calgliari-Sassari, 28-1X-4-X, Edizioni Cremononese Roma, 1964, 130-153.

[2] J. SERrin, The initial value problem for the Navier-Stokes equations, in: Proc. Symp. Nonlinear Problemsw, University of Wisconsin Press, Madison, WI, 1963, pp. 69-98.

[3] C. H. Lin And L. E. Payne, Continuous dependence on the Soret coefficient for double diffusive convection in Darcy flow, J. Math. Anal. Appl., 342 (2008) 311-325.

[4] C. H. Hardy, J. E. Littlewood and G. Polya, Inequalities; Cambridge Univ. Press, 1953.

[5] D. S. Mitronovic, Analytical Inequalities, Springer-Verlag, 1970.

[6] J. L. LIONS, R. TEMAM AND S. WANG, New formulations of the primitive equations of atmosphere and applications, Nonlinearity, 5 (1992) 237-288.

[7] J. L. Lions, R. TEmam AND S. WANG, On the equations of the large-scale ocean, Nonlinearity, 5 (1999) 1007-1053.

[8] J. L. Lions, R. Temam And S. WANG, Models of the coupled atmosphere and ocean (CAOI), Computational Mechanics Advance, 1 (1993) 1-54.

[9] J. L. Lions, R. Temam And S. WAnG, Mathematical theory for the coupled atmosphere-ocean models (CAOIII), J. Math. Pures Appl., 74 (1995), 105-163.

[10] D. W. HuAng, T. L. Shen AND Y. ZHEnG, Ergodicity of two-dimensional primitive equations of large scale ocean in geophysics driven by degenerate noise, Applied Mathematics Letters, 102 (2020) 106146, https://doi.org/10.1016/j.aml.2019.106146.

[11] B. YOU AND F. LI, Global attractor of the three-dimensional primitive equations of large-scale ocean and atmosphere dynamics, Z. Angew. Math. Phys, 69 (2018) 114.

[12] Q. JIU, M. J. LI AND F. WANG, Uniqueness of the global weak solutions to 2D compressible primitive equations, J. Math. Anal. Appl., 461 (2018) 1653-1671.

[13] E. Chiodaroli And M. MicháleK, Existence and Non-uniqueness of Global Weak Solutions to Inviscid Primitive and Boussinesq Equations, Commun. Math. Phys., 353 (2017) 1201-1216.

[14] J. Y. SUn AND S. B. CUI, Sharp well-posedness and ill-posedness of the three-dimensional primitive equations of geophysics in Fourier-Besov spaces, Nonlinear Analysis: Real World Applications, 48 (2019) 445-465.

[15] D. F. FANG AND B. HAN, Global well-posedness for the 3D primitive equations in anisotropic framework, J. Math. Anal. Appl., 484 (2020) 123714, https://doi.org/10.1016/j.jmaa.2019.123714. 
[16] M. W. Hirsch and S. Smale, Differential Equations, Dynamical Systems, and Linear Algebra, Academic Press, New York, 1974.

[17] Y. F. LI, Continuous dependence on the viscosity coefficient for the primitive equations, Journal of Shandong University (Natural Science), 54 (2019) 12-23.

[18] Y. F. LI, Continuous Dependence on Boundary Parameters for Three-Dimensional Viscous Primitive Equation of Large-Scale Ocean Atmospheric Dynamics, Journal of Jilin University (Science Edition), 57 (2019) 1053-1059.

[19] B. L. GUO AND D. W. HUANG, Existence of weak solutions and trajectory attractors for the moist atmospheric equations in geophysics, Journal of mathematical physics, 47 (2006) 1089-7658.

[20] B. L. GUO AND D. W HUANG, Existence of the universal attractor for the $3 D$ viscous primitive equations of large-scale moist atmosphere, Journal of Differential Equations, 251 (2011) 457-491. 